\title{
Improved thermal stability of an organic zeolite by fluorination
}

\author{
Katharina Reichenbächer · Gaëtan Couderc · Antonia Neels · \\ Karl Krämer $\cdot$ Edwin Weber · Jürg Hulliger
}

Received: 13 September 2007/Accepted: 8 December 2007/Published online: 25 December 2007

(C) Springer Science+Business Media B.V. 2007

\begin{abstract}
The thermal stability of an organic zeolite material, namely 2,4,6-tris(4-bromo-3,5-difluorphenoxy)1,3,5-triazin (Br-3,5-DFPOT), was improved by fluorination of 2,4,6-tris(4-bromophenoxy)-1,3,5-triazin (BrPOT). The open pore structure (van der Waals diameter of $10.5 \AA$ ) of the modified zeolite was observed up to $110^{\circ} \mathrm{C}$ in comparison to $70{ }^{\circ} \mathrm{C}$ for BrPOT. Nitrogen sorption at low temperature showed a type I isotherm and derived pore volumes thereof are in agreement with structural data. It was observed here that Br-3,5-DFPOT crystals preserving the open pore structure could only be obtained below a typical size of about $50 \mu \mathrm{m}$. The improved thermal stability of the fluorinated system is attributed to an enhancement of the strength of the $\mathrm{Br}_{3}$-synthon.
\end{abstract}

Keywords Fluorine bonds - Host-guest system .

Organic zeolites $\cdot$ Sorption isotherm

\section{Introduction}

Organic molecules forming a solvent free open pore solid state structure by the effect of a template can still be considered an exception [1]. The van der Waals size of

K. Reichenbächer · G. Couderc · K. Krämer · J. Hulliger $(\bowtie)$

Departement of Chemistry and Biochemistry, University of Berne, Freiestrasse 3, 3012 Berne, Switzerland

e-mail: publication.hulliger@iac.unibe.ch

A. Neels

Institute of Microtechnology, University of Neuchâtel, Jacquet Droz 1, 2002 Neuchatel, Switzerland

E. Weber

Institute of Organic Chemistry, TU Bergakademie Freiberg, Leipziger Str. 29, 09596 Freiberg/Sachsen, Germany known examples of such empty channels is ranging in between 5 and $12 \AA$. In comparison to aluminosilicates [2] and metal organic frameworks (MOF) [3], the thermal stability of organic zeolites is, however, lower. So far, temperatures up to $300{ }^{\circ} \mathrm{C}$ were reported for architectures featuring strong hydrogen bondings [4]. In the case of tris(o-phenylendioxy)-cyclotriphosphazen (TPP), showing predominantly van der Waals interactions, an upper limit for empty channels up to $150{ }^{\circ} \mathrm{C}$ was reported [5], however, results depend on the crystal size and polymorph purity. A lower thermal stability in comparison to MOF's seems reasonable, because of missing ionic coordinative bonds in the structure.

Documented by an increasing number of systems, the existence of open pore organic zeolite materials seems to depend on the crystal size [4]. Evidently, below a size of $50-100 \mu \mathrm{m}$, the thermal stability can be increased significantly. The reason for this behaviour is seen in a critical limit for stress, which may accumulate in larger crystals: Crystals larger than $100 \mu \mathrm{m}$ typically show fractures and fractions of the volume having transformed into guest free native structure [4]. Contrary, crystals being small enough may stay unaffected. Because applications in the sorption of gases use a small size of crystals, this property matches a basic requirement [1].

Small size guest molecules included in e.g. TPP show a type I sorption isotherm, essentially favoured by the coordinative property of phenyl fragments (Xenon $[1,6]$ ) building up the channel wall. Given by examples of large size (10-12 ̊) channels, e.g. 2,4,6-tris(4-bromophenoxy)1,3,5-triazin (BrPOT), coordination to the adsorbed molecule is much weaker but still type I isotherms are likely to observe at low temperature. In the case of BrPOT, the coordination effect for small guest molecules is certainly weaker due to a wider pore diameter. 
In view of previous results [1, 4] we may ask: (i) How the size of open pores might be increased and, related to the issue of size, (ii) how one could improve the thermal stability of organic zeolites?

Because of missing structural cationic coordination centres and a decreasing strength for coordination to the adsorbed molecule at larger pore size, we anticipate that increasing the size to values larger than 10-12 $\AA$ may not be feasible for the sorption of gases at low partial pressure and ambient temperature. An example is again known by TPP (5 ̊) which can up take $\mathrm{Xe}(\mathrm{g})$ at 1 bar and $25^{\circ} \mathrm{C}$ probably due to an overlap of the atomic functions of Xenon to the phenyl group forming the wall of the cavity [6]. Apparently, an evident goal is to increase the thermal stability of organic zeolites.

\section{Experimental part}

Sample preparation

The zeolite was prepared by a two steps procedure: (1) Preparation of the inclusion compound Br-3,5DFPOT. $\left(\mathrm{CS}_{2}\right)$ trough sorption of $\mathrm{CS}_{2}(\mathrm{~g})$ by the solid guestfree compound. For this solid starting material (ball milled to a size smaller than $1 \mu \mathrm{m}$ ) was exposed to the gaseous atmosphere above $\mathrm{CS}_{2}(\mathrm{l})$ at $300 \mathrm{~K}$. (2) Desorption of $\mathrm{CS}_{2}(\mathrm{~g})$ at $10^{-2} \mathrm{~m}$ bar during 5 days at room temperature was producing small crystals of the open pore material.

Elemental analysis (\% mass)

BrPOT (guest-free channel compound): measured: C: 43.07, H: 2.23, N: 6.92, S: <0.3; calculated: C: 42.46, H: 2.04, N: 7.07. S: 0; Br-3,5-DFPOT (guest-free channel compound): measured: C: 35.92, H: 0.88, N: 5.80, S: <0.3; calculated: C: 35.93, H: 0.86, N: 5.99 .

\section{Powder X-ray}

Temperature dependent X-ray powder diffractograms were measured on a Stoe StadiP diffractometer with Ge-monochromator, $\mathrm{CuK}_{\alpha 1}$ and a linear detector in Debye-Scherrer geometry. Stoe StadiP $\left(\mathrm{CuK}_{\alpha}\right)$ : $50-130^{\circ} \mathrm{C}$ : in steps of $20{ }^{\circ} \mathrm{C}, 130-150{ }^{\circ} \mathrm{C}$ : in step of $10{ }^{\circ} \mathrm{C}$.

\section{Sorption properties}

The sorption isotherms were obtained from a CE Instruments Sorptomatic (1990) Systems. Crystals of $\sim 50 \mu \mathrm{m}$ were treated in vacuum $\left(10^{-4}\right.$ mbar $)$ at $50{ }^{\circ} \mathrm{C}$ for 1 day.
The measurements were performed at $-196{ }^{\circ} \mathrm{C}$. The pressure was measured by an absolute pressure sensor (MKS622A13TDD).

Single crystal structure analysis

An empty channel single crystal of Br-3,5-DFPOT was obtained from crystallization by $\mathrm{CS}_{2}$ evaporation followed by desorption of the guest molecules in the vacuum. A transparent and crack free crystal of the size of $0.2 \times 0.2 \times$ $0.3 \mathrm{~mm}^{3}$ of Br-3,5-DFPOT was mounted on a Stoe Mark IIImaging Plate diffractometer system [7] equipped with a graphite monochromator. Data collection was performed at $-100{ }^{\circ} \mathrm{C}$ using $\mathrm{Mo}-\mathrm{K}_{\alpha}$ radiation $(\lambda=0.71073 \AA) .120$ exposures ( $0.5 \mathrm{~min}$ per exposure $)$ were obtained at an image plate distance of $135 \mathrm{~mm}$ with $\varphi=0^{\circ}$ and $0<\omega<180^{\circ}$ with the crystal oscillating through $1.5^{\circ}$ in $\omega$. The structure was solved by direct methods using the program SHELXS92 [8] and refined by full matrix least squares on $F^{2}$ with SHELXL-97 [9]. The hydrogen atoms were included in calculated positions and treated as riding atoms using SHELXL-97 default parameters. A semi empirical absorption correction was applied using MULscanABS (PLATON03 [10], $T_{\min }=0.378, T_{\max }=0.515$ ). The volume of the channel was estimated to $1,166 \AA^{3}$ using the SQUEEZE option, because no stable refinement could be obtained due to small quantities of undetermined guest molecules remaining inside the channels (see main text). The crystallographic data are reported in Table 1.

\section{Results and discussion}

Here we report on zeolitic properties of a new fluorinated channel structure 2,4,6-tris(4-bromo-3,5-difluorophenoxy)1,3,5-triazin (Br-3,5-DFPOT) [11] in comparison to BrPOT

Table 1 Single crystal data measured

\begin{tabular}{ll}
\hline Br-3,5-DFPOT & \\
\hline System & Trigonal \\
Group & $\mathrm{P} \overline{3} 1 \mathrm{c}$ \\
$a / \AA$ & $16.072(3)$ \\
$b / \AA$ & $16.072(3)$ \\
$c / \AA$ & $14.111(3)$ \\
$a /^{\circ}$ & 90 \\
$b /^{\circ}$ & 90 \\
$c /^{\circ}$ & 120 \\
Volume $/ \AA^{3}$ & $3156.6(9)$ \\
$Z$ & 4 \\
Density $\left(\mathrm{g} \mathrm{cm}^{-3}\right)$ & 1.477 \\
\hline
\end{tabular}


[4], as well as an improvement of thermal stability of the nanoporous structure by fluorination. The zeolite modifications of Br-3,5-DFPOT and BrPOT (average size of crystallites $\sim 50 \mu \mathrm{m}$ ) were prepared by a solid state reaction using $\mathrm{CS}_{2}(\mathrm{~g})$ sorption and guest free material, followed by desorption of $\mathrm{CS}_{2}(\mathrm{~g})$ in the vacuum at $25^{\circ} \mathrm{C}$. As shown by elemental analysis, the sulphur content was below detection limit. Therefore, just after desorption a material free of template was obtained.<smiles>Fc1cc(Oc2nc(Oc3cc(F)c(Br)c(F)c3)nc(Oc3cc(F)c(Br)c(F)c3)n2)cc(F)c1Br</smiles>

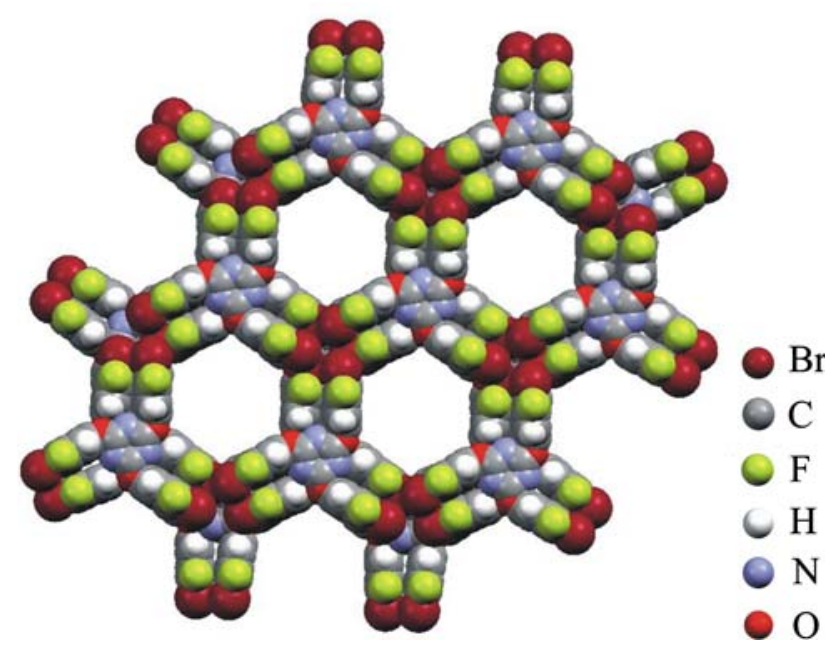

Fig. 1 Molecular structure of Br-3,5-DFPOT and its solid viewed along the c-axis of the channel structure. The van der Waals diameter of channels is about $10.5 \AA$
Larger crystals of Br-3,5-DFPOT were obtained by isothermal evaporation of $\mathrm{CS}_{2}(\mathrm{l})$ (room temperature and flux of $\mathrm{N}_{2}$ at 1 bar) followed by a desorption in the vacuum $\left(P=10^{-2} \mathrm{~m}\right.$ bar) at $25^{\circ} \mathrm{C}$. Although most of the material converted into the dense phase, some guest free $\mathrm{Br}-3,5$ DFPOT crystals of a size large enough for single crystal diffraction $\left(\sim 0.2 \times 0.2 \times 0.3 \mathrm{~mm}^{3}\right)$ were nevertheless obtained. Also in this case an elemental analysis confirmed a complete loss of template molecules. A single crystal diffraction analysis of transparent crystals showing a hexagonal morphology revealed the channel architecture as shown in Fig. 1.

The host molecules are aligned parallel to the $(a, b)-$ plane and linked by $\mathrm{Br}_{3}$-synthons. The stacking of these layers along the c-axis results in the formation of hexagonal channels providing a van der Waals diameter of $\sim 10.5 \AA$.

The thermal stability of the zeolite type modification of $\mathrm{Br}-3,5-\mathrm{DFPOT}$ was investigated by temperature dependent $\mathrm{X}$-ray powder diffraction. In comparison to BrPOT being stable up to about $70{ }^{\circ} \mathrm{C}$, fluorination yielded a thermal stability up to about $110^{\circ} \mathrm{C}$. However, above $130{ }^{\circ} \mathrm{C}$, the channel structure efficiently transformed into the more densely packed monoclinic structure (Fig. 2).

The sorption of $\mathrm{N}_{2}(\mathrm{~g})$ at $T=-196{ }^{\circ} \mathrm{C}$ performed for both BrPOT and $\mathrm{Br}-3,5$-DFPOT showed a type I isotherm (Brunauer's classification [12]) reflecting clearly zeolitic properties of the frameworks (Fig. 3). The pore volume $\left(W_{0}=N_{0}^{a} \cdot W_{m}\right)$ was determined using the DubininAsthakov equation, which in the case of other organic zeolites has given reasonable results [13]:

$N^{a}=N_{0}^{a} \exp \left[-(A / E)^{n}\right]$,

where $A=-\Delta G=R T \ln \left(P_{0} / P\right), N^{\mathrm{a}}\left(10^{-3} \mathrm{~mol} \mathrm{~g}^{-1}\right)$ being the molar quantity of the adsorbed material per gram of zeolite, $N_{0}^{a}$ represents the maximum up take of gas, $E$ is an energy parameter and $\mathrm{n}$ is an exponent characterizing the homogeneity of the adsorbing inner surface (typical values: $n=2-5$ ). In the present case best fit was obtained for $E=2.5 \mathrm{~kJ} \mathrm{~mol}^{-1}$ (BrPOT) and $3.0 \mathrm{~kJ} \mathrm{~mol}^{-1}(\mathrm{Br}-3,5-$ POT) with $n=2$ for both materials. From these data we can
Fig. 2 Temperature dependence of powder diffraction data of BrPOT and $\mathrm{Br}-3,5$-DFPOT
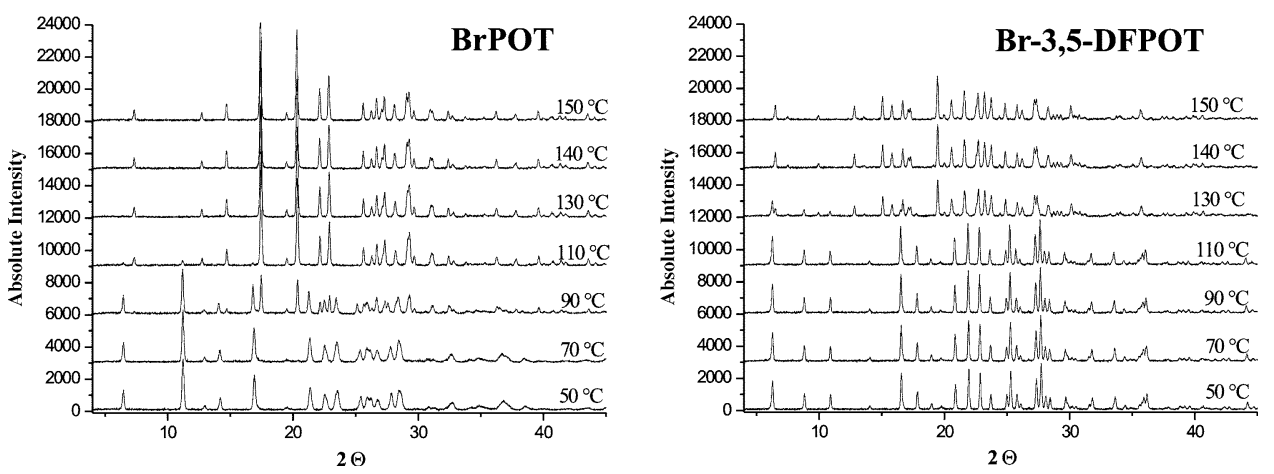


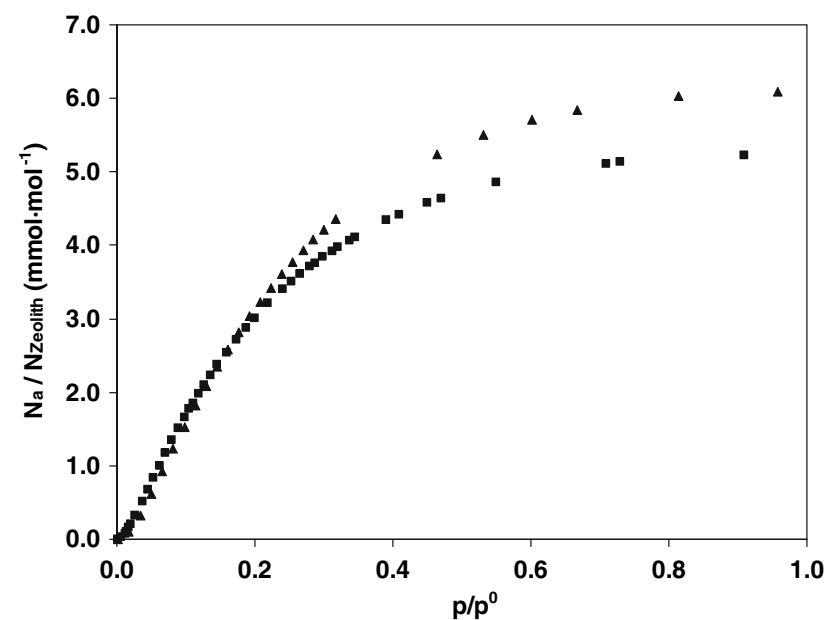

Fig. 3 Sorption isotherm of $\mathrm{N}_{2}$ at $T=-196{ }^{\circ} \mathrm{C}$ for BrPOT (triangles) und Br-3,5-DFPOT (squares)

conclude that a homogeneous distribution of the adsorption site is found inside channels. The derived specific pore volumes $W_{0}=0.174(6) \mathrm{cm}^{3} \mathrm{~g}^{-1}$ (gram of BrPOT) and $W_{0}=0.151(5) \mathrm{cm}^{3} \mathrm{~g}^{-1}$ (gram of Br-3,5-DFPOT) are in good agreement with the calculated volumes using the van der Waals size of the channels $W_{0}$ (calc.) $=0.169 \mathrm{~cm}^{3} \mathrm{~g}^{-1}$. This allows to conclude that during sorption the channel structures is preserved, whereas in some cases of MOF systems structural changes have been observed [3].

\section{Conclusion}

The present analysis shows clearly a stabilizing effect of fluorination of host molecules in the case of a purely organic zeolite material featuring relatively large open pores of 10-11 Å. Most likely, Piedford units, a few hydrogen bonds and in particular an enhancement of the $\mathrm{Br}_{3}$-synthon by fluorination are responsible for an enhanced stability of Br-3,5-DFPOT. Similar effects have been observed in the case of other fluorinated solids [14]. Interesting inclusion properties of Br-3,5-DFPOT for various large size functional molecules were recently presented [11].

Acknowledgement This work was supported by the Swiss SNF 200021-113358/1.

\section{References}

1. Organic Zeolite: Sozzani, P., Comotti, A., Simonutti, R., Meersmann, T., Logan, J.W., Pines, A.: A porous crystalline molecular solid explored by hyperpolarized Xenon. Angew. Chem. Int. Ed. 39, 2695-2699 (2000); Hertzsch, T., Hulliger, J., Weber, E., Sozzani, P.: In: Atwood, J.L., Steed, J.W. (eds.) Encyclopedia of Supramolecular Chemistry. Marcel Dekker, New York (2004); Soldatov, D.V., Ripmeester, J.A.: Organic zeolites. Stud. Surf. Sci. Catal. 156, 37-54 (2005); Lee, S., Venkataraman, D.: Organic zeolites? Stud. Surf. Sci. Catal. 102, 75-95 (1996); Görbitz, C.H.: An exceptionally stable peptide nanotube system with flexible pores. Acta Cryst. B58, 849-854 (2002); Soldatov, D.V., Moudrakovski, I.L., Ripmeester, J.A.: Organic zeolites: dipeptides as microporous materials. Angew. Chem. Int. Ed. 43, 6308-6311 (2004); Yang, J., Dewal, M.B., Shimizu, L.S.: Self-assembling bisurea macrocycles used as an organic zeolite for a highly stereoselective photodimerization of 2-cyclohexenone. J. Am. Chem. Soc. 128, 8122-8123 (2006)

2. Smith, J.V.: Origin and structure of zeolites, ACS Monograph 171 (Zeolite Chem. Catal.), 3 (1976); Yamamoto, K., Nohara, Y., Domon, Y., Takahashi, Y., Sakata, Y., Plévert, J., Tatsumi, T.: Organic-inorganic hybrid zeolites with framework organic groups. Chem. Mater. 17, 3913-3920 (2005)

3. MOF: Kitagawa, S., Kitaura, R., Noro, S.-I.: Functional porous coordination polymers. Angew. Chem. Int. Ed. 43, 2334-2375 (2004); Rosseinsky, M.J.: Recent developments in metal-organic framework chemistry: design, discovery, permanent porosity and flexibility. Micropor Mesopor Mater. 73, 15-30 (2004); Rowsell, J.L.C., Yaghi, O.M.: Metal-organic frameworks: a new class of porous materials. Micropor Mesopor Mater. 73, 3-14 (2004); Mueller, U., Schubert, M., Teich, F., Puetter, H., Schierle-Arndt, K., Pastré, J.: Metal-organic frameworks-prospective industrial applications. J. Mater. Chem. 16, 626-636 (2006)

4. Suess, H.I., Hulliger, J.: Organic channel inclusion compound featuring an open pore size of $12 \AA$. Micropor Mesopor Mater. 78, 23-27 (2005)

5. Sozzani, P., Bracco, S., Comotti, A., Feretti, L., Simonutti, R.: Methane and carbon dioxide storage in a porous van der Waals crystal. Angew. Chem. Int. Ed. 44, 1816-1820 (2005)

6. Couderc, G., Hertzsch, T., Behrnd, N.-R., Krämer, K., Hulliger, J.: Reversible sorption of nitrogen and xenon gas by the guestfree zeolite tris(o-phenylenedioxy)cyclotriphosphazene (TPP). Micropor Mesopor Mater. 88, 170-175 (2006)

7. Stoe \& Cie. IPDS Software. Stoe \& Cie GmbH, Darmstadt, Germany (2005)

8. Sheldrick, G.: Phase annealing in SHELX-90: direct methods for larger structures. Acta Cryst. A46, 467-473 (1990)

9. Sheldrick, G.: SHELXL-97, program for crystal structure refinement. University of Göttingen, Germany (1997)

10. Spek, A.: Single-crystal structure validation with the program PLATON. J. Appl. Cryst. 36, 7-13 (2003)

11. Reichenbächer, K., Neels, A., Stoeckli-Evans, H., Balasubramaniyan, P., Müller, K., Weber, E., Hulliger, J.: New fluorinated channel-type Host-guest compounds. Cryst. Growth Des. 7, 1399-1405 (2007)

12. Brunaeur, S.: The adsorption of gases and vapors, vol. 1. Princeton Uni Press, Princeton (1943)

13. Dubinin, M.M., Astakhov, V.A.: Description of adsorption equilibriums of vapors on zeolites over wide ranges of temperature and pressure. Adv. Chem. 102, 69-85 (1971)

14. Metrangolo, P., Resnati, G.: Halogen bonding: a paradigm in supramolecular chemistry. Chem. Eur. J. 7, 2511-2519 (2001) 